https://doi.org/10.7203/Normas.4.4692

\title{
«LA LETRA... POR LA VISTA ENTRA». A PROPÓSITO DE LA NUEVA NORMATIVA SOBRE EL USO DE LAS MAYÚSCULAS Y SU APLICACIÓN EN LOS TEXTOS DE ENSEÑANZA
}

\author{
«A CAPITAL ISSUE» REGARDING THE NEW SPELLING RULES ON THE USE OF \\ CAPITAL LETTERS AND THEIR APPLICATION IN SCHOOL TEXTBOOKS
}

Amparo RICÓs VIDAL

Universitat de València

Adela GARCÍA VALLE

Universitat de València

\section{RESUMEN:}

El propósito de este artículo consiste en analizar el uso de las mayúsculas en una serie de manuales posteriores a 2010 y determinar los aspectos que plantean mayores problemas u ofrecen diferentes soluciones, con la finalidad última de divulgar los aspectos pendientes de una mejor regulación, hacer hincapié en la importancia de criterios claros en la aplicación práctica de las normas y en la responsabilidad de los profesionales del sector editorial, puesto que en la adquisición y aprendizaje de la ortografía es fundamental la memoria visual. El análisis muestra que las mayores dificultades se hallan en la función identificativa de las mayúsculas y se centran en los aspectos más novedosos y con mayor repercusión social (tratamientos, títulos o cargos). La causa de estos errores se puede explicar por la densidad y complejidad de la obra académica, que no favorece su consulta, y por la necesidad de conocimientos extralingüísticos en algunas opciones, no siempre al alcance de un público medio no experto. Por último, si bien se señala la responsabilidad de muchas de las editoriales en la salvaguarda de las normas ortográficas, cabe insistir en la necesidad de directrices claras en los libros de estilo de las editoriales para evitar soluciones diversas en un mismo manual, además de un mayor cuidado en las reediciones de los textos, entre otras cuestiones.

PALABRAS CLAVE: Ortografía, mayúscula, manual, educación.

\section{ABSTRACT:}

The purpose of this article is to analyze the use of capital letters in a series of handbooks published after 2010 and identify aspects which pose major problems or offer novel solutions, in order to disseminate those problematic aspects still in need of improved regulation, emphasize the importance of clear criteria in the application of the standards and draw attention to the 
responsibility of professionals in the publishing sector, since visual memory is crucial in the acquisition and learning of spelling. The analysis shows that the greatest difficulties are found in the identifying function of capital letters and are focused on the most innovative regulatory aspects and those with the greatest social impact (ways of addressing people, titles or positions). These mistakes are caused by the density and complexity of academic publications of this type that are difficult to consult and the need for extralinguistic knowledge regarding some options, which are not always obvious to an average audience of laypersons. Finally, although the responsibility of many of the publishing houses to follow spelling rules is highlighted, emphasis should also be placed on the need for clear guidelines in stylebooks in order to avoid diverse solutions in the same handbook, as well as the need for careful attention when reediting texts, among other issues.

KEY WORDS: Spelling, capital letters, handbook, education.

Lo que la Real Academia Española cree, con todas las Academias asociadas, es que un código tan ampliamente consensuado merece respeto y acatamiento, porque, en última instancia, los hispanohablantes hemos de congratularnos de que nuestra lengua haya alcanzado con él un nivel de adecuación ortográfica que no muchos idiomas poseen. (RAE: Ortografía de la lengua española. 1999. pág. XVIII)

\section{INTRODUCCIÓN}

Es innegable que en toda nuestra vida, pero especialmente en la época adulta, la comunicación escrita domina gran parte de nuestra actividad social y económica. Hablar y escribir correctamente se convierten de este modo en un elemento fundamental de la imagen personal que nos caracteriza y que ofrecemos al resto del mundo, sobre todo a los usuarios que comparten nuestro idioma.

Sin embargo, alcanzar este objetivo no es una tarea fácil; al contrario, supone un esfuerzo arduo aunque necesario para avanzar y progresar socialmente, pues así nos lo exige la sociedad actual, inmersa en un constante intercambio de «documentos», desde los cuentos que nos encandilaban con las ilustraciones cuando nos iniciábamos en la lectura, pasando por los primeros cuadernos, los libros de texto, las lecturas juveniles, la prensa, los apuntes de clase... hasta llegar a las facturas, las declaraciones de renta, las recetas médicas, las revistas del corazón y un largo etcétera en el que se incluyen también los propios de la era de la información (blogs, redes sociales,...). Todos ellos van marcando nuestras vidas desde niños, haciéndonos «competentes» textual y lingüísticamente.

En este proceso de aprender a hablar y a escribir correctamente la meta es alcanzar la expresión culta formal: el español estándar, entendido como:

...la lengua que todos empleamos, o aspiramos a emplear, cuando sentimos la necesidad de expresarnos con corrección; la lengua que se enseña en las escuelas; la que, 
con mayor o menor acierto, utilizamos al hablar en público o emplean los medios de comunicación; la lengua de los ensayos y de los libros científicos y técnicos. Es, en definitiva, la que configura la normativa, el código compartido que hace posible que hispanohablantes de muy distintas procedencias se entiendan sin dificultad y se reconozcan miembros de una misma comunidad lingüística (DPD: XIV).

Y esa normativa es la que se expone y recoge en las últimas obras académicas, fruto del trabajo conjunto de las Academias de la Lengua Española: el Diccionario panhispánico de dudas, la Nueva gramática de la lengua española y la Ortografía de la lengua española.

En este aspecto, la ortografía es uno de los elementos al que prestamos más atención, no por ser el más importante, sino porque es el más aparente visualmente:

No podemos olvidar que nuestra ortografía es nuestra presentación social al escribir: se nos cataloga por nuestra manera de escribir, una falta de ortografía en nuestros escritos nos marca socialmente, quizá con mayor notoriedad que una pronunciación vulgar, pues sabido es que verba volant, scripta manent (Paredes, 1997: 612).

Escribir con corrección es, sin duda, un rasgo de prestigio social:

Es cierto que para determinados segmentos de la población la correcta ortografía carece de interés; no obstante, son todavía amplios los sectores que la siguen considerando como un rasgo de prestigio y, aunque solo sea una marca formal de la lengua escrita, es un aspecto relevante e imprescindible para el bien hacer con la lengua (González, 1999: 61).

Son muchos los que consideran que el conocimiento y la puesta en práctica de las normas ortográficas redundan en una buena imagen de los usuarios de la lengua en la sociedad:

La ortografía se concreta en un conjunto de normas que deben ser respetadas por todos los hablantes que deseen escribir con corrección. Su incumplimiento da lugar a las comúnmente denominadas faltas de ortografía. El conocimiento de las normas ortográficas es condición necesaria para el completo desarrollo del individuo, ya que es indisociable de la adquisición de las destrezas básicas de la lectura y la escritura. Es la propia sociedad la que recompensa a quienes dominan la ortografía con una buena imagen social y profesional y, en sentido contrario, la que sanciona a las personas que muestran una ortografía deficiente con valoraciones que afectan a su imagen y pueden restringir su promoción académica y profesional (OBLE, 2012: XXI).

No obstante, el dominio ortográfico sigue siendo uno de los talones de Aquiles en la adquisición de la escritura en los distintos niveles educativos, bien porque el método empleado no ha sido el más adecuado (Paredes, 1997, 1999; González, 1999), bien porque sigue habiendo cierto desinterés en determinados sectores sociales, bien porque el lenguaje oral ha adquirido un estatus que antes no poseía (OLE, 2010: XXXIX), bien porque existe cierta permisividad al respecto, una postura laxa que añade obstáculos al aprendizaje de la norma ortográfica, motivada principalmente por que en los estudios prima el contenido frente a la expresión: 
...la experiencia nos ha demostrado que las deficiencias que los alumnos arrastran desde la Educación Primaria se mantienen a lo largo de la Educación Secundaria y permanecen hasta llegar a la Universidad, e incluso cuando la abandonan tras la conclusión de los estudios superiores. La permisividad ante la incorrección alcanza incluso a la Universidad [...] Lo que interesa es que el alumno posea los contenidos, mas no importa cómo los exprese (González, 1999: 61).

Y este hecho no ha cambiado en las dos últimas décadas, a pesar de que las autoridades educativas prestan especial atención a estos aspectos tanto en la $\mathrm{LOE}^{1}$ como en la $\mathrm{LOMCE}^{2}$, haciendo en ambas leyes incidencia en la necesidad de una metodología inductiva.

El cambio de método didáctico, favorecido y apoyado por las nuevas normativas educativas, se debe también a que «el aprendizaje de la ortografía se relaciona con procesos psicolingüísticos y neurológicos propios, y da lugar a rutas que activan capacidades específicas, que se encuentran con dificultades singulares y generan problemas no compartidos» (OLE, 2010: XXXIX-XL). Entre los factores psicolingüísticos, destaca la memoria visual y su relación con la conciencia fonológica (Paredes, 1997; Pino-Bravo, 2005) $)^{3}$.

${ }^{1}$ LEY ORGÁNICA 2/2006, de 3 de mayo, de Educación. BOE, 4 de mayo de 2006. En el currículo de ESO de la Comunidad Valenciana -DECRETO 112/2007, de 20 de julio, del Consell [2007/9717] DOCV (24/07/2007)-, se dedica el tercer párrafo del bloque 3 (Conocimiento de la lengua) a la Fonética y Ortografía: Correspondencia entre sonidos y grafías. El alfabeto y los dígrafos. Vocales abiertas y cerradas. La sílaba. Principales esquemas silábicos. Diptongos, triptongos e hiatos. Nociones básicas de acentuación y puntuación. Uso de la diéresis. Conocimiento y uso reflexivo de las normas ortográficas, su valor social y la necesidad de ceñirse a la norma lingüística en los escritos. Lo mismo ocurre en el currículo de Bachillerato (BOE, Orden ESD /1729/2008, 11 de junio 2008).

${ }^{2}$ En el borrador de los contenidos expuestos al público el pasado mes de julio en la página del Ministerio, se considera relevante el dominio de las habilidades linguísticas y el uso reflexivo de la lengua. De este modo, «el Conocimiento de la Lengua se plantea como el aprendizaje progresivo de las habilidades lingüísticas, así como la construcción de competencias en los usos discursivos del lenguaje a partir del conocimiento y la reflexión necesarios para apropiarse de las reglas ortográficas y gramaticales imprescindibles, para hablar, leer y escribir correctamente en todas las esferas de la vida [...]. La reflexión metalingüística está integrada en la actividad verbal y en todos los niveles: discursivo, textual y oracional, e interviene en los procesos de aprendizaje de la lengua oral y la lengua escrita a través de las diferentes fases de producción: planificación, textualización y revisión, lo que aportará al alumnado los mecanismos necesarios para el conocimiento activo y autónomo de su propia lengua a lo largo de la vida». De ahí que uno de los estándares de aprendizaje sea la revisión del producto escrito «5.3. Revisa el texto en varias fases para aclarar problemas con el contenido (ideas y estructura) o la forma (puntuación, ortografía, gramática y presentación) evaluando su propia producción escrita o la de sus compañeros».

${ }^{3}$ «Muchas veces sabemos cómo se escribe una palabra por la forma con la que recordamos haberla visto escrita. De ahí la importancia que todos otorgan a la lectura: un buen hábito lector favorece el asentamiento de la forma de las palabras» (Paredes, 1997: 613); «Estos resultados no solo adquieren relevancia en el ámbito de las prácticas pedagógicas en la educación preescolar, puesto que incentivan a afianzar actividades en las cuales los niños puedan ejercitar la percepción de signos gráficos, la memoria visual y la atención para reconocer diferencias gráficas sutiles. También abre nuevos horizontes de estudio para tratar de conocer mejor la relación entre la memoria visual y la conciencia fonológica» (Pino-Bravo, 2005). 
Teniendo en cuenta la importancia que adquiere, junto a otros factores, la memoria visual, es responsabilidad de los profesionales del lenguaje, desde el profesorado que trabaja día a día en el aula hasta las empresas que editan los manuales escolares, cuidar la corrección ortográfica del material empleado en las clases en todos los niveles educativos. Este es, pues, el objeto de este artículo: analizar la aplicación de la nueva normativa académica, expuesta en la Ortografía de 2010, en la edición de los libros de textos de distintos ciclos educativos, publicados a partir de esta fecha. Para ello se ha restringido el análisis a un aspecto complejo, problemático y difícil, considerado en ocasiones secundario, como es el uso de las mayúsculas y las minúsculas. El corpus está formado por quince manuales de distintas editoriales, diferentes ciclos y varias asignaturas. El objetivo final es, por un lado, determinar los aspectos que plantean mayores problemas u ofrecen diferentes soluciones en la edición de textos y, por otro, extraer conclusiones acerca de la dificultad o la carencia de normas claras sobre dichos puntos con el propósito último de divulgar aquellos aspectos pendientes de una mejor regulación y hacer hincapié en la importancia de criterios claros en la aplicación práctica de las normas.

\section{LAS OBRAS ACADÉMICAS Y LAS REGLAS SOBRE EL USO DE LAS MAYÚSCULAS}

Como indica José Martínez de Sousa, en la introducción del Diccionario de uso de las mayúsculas y minúsculas (2007: 11): «Entre los temas ortográficos, tal vez sea este uno de los más complejos, si no el que más». Sin embargo, la atención de la Academia a este aspecto no ha sido nunca excesiva a lo largo de su historia. Las normas sobre las mayúsculas han sido insuficientes o inexistentes en la mayoría de las obras precedentes. No será hasta la Ortografía de 1999 cuando se dedique mayor espacio y un nuevo tratamiento a este punto y se recoja de manera ordenada y clara apuntes que estaban presentes de forma aislada y no coherente en publicaciones anteriores, académicas y no académicas. Esta primera redacción de 1999 sirve de base para confeccionar el artículo temático sobre las mayúsculas en el Diccionario panhispánico de dudas, de 2005. En esta ocasión, se trata con mayor extensión y orden el uso de las mayúsculas y minúsculas y se clarifican muchos de los aspectos sobre los que había dudas $^{4}$.

La Ortografía de 2010 les dedica todo un capítulo, casi un $10 \%$ del total de la obra $^{5}$. Los cambios que afectan a las mayúsculas en la edición actual no son muchos y todos ellos se plantean en relación con la función identificativa y la tendencia a la minusculización que caracteriza esta última publicación: el uso de minúscula inicial en lugar de mayúscula en las fórmulas de tratamiento (don, su excelencia, usted, san...), en títulos y cargos (el papa, el rey, la presidenta...), en los pronombres personales en textos religiosos (a ti rogamos, Virgen María), en los sustantivos genéricos que aparecen seguidos de un adjetivo derivado del topónimo (península ibérica, las islas

\footnotetext{
${ }^{4}$ Para un breve resumen de la aportación de las obras académicas y no académicas a la normativa referente a las mayúsculas, véase Martínez de Sousa (2007: 17-22).

${ }^{5}$ Capítulo IV «El uso de las letras mayúsculas y minúsculas», pp. 441-517.
} 
británicas...) -aunque no en los usos antonomásticos (la Península, las Islas...)-, o el artículo que forma parte del nombre de las comarcas (el Bierzo, la Alcarria ... $)^{6}$; el resto confirma, razona y ejemplifica las normas presentes ya en el $D P D$, no tan conocidas entre el público medio o los profesionales del lenguaje, como se ha podido comprobar en el análisis del corpus.

Si bien esto supone un avance en la normativización del empleo de este tipo de letra y su divulgación entre el público medio, varios son los motivos que pueden considerarse a la hora de entender las «faltas de ortografía en el uso de la mayúscula» y que no han sido resueltos con plena satisfacción. Por un lado, cabe mencionar el carácter subjetivo, o dejado a la interpretación del escribiente, que plantean estas normas y que se mantiene actualmente:

El hecho de que la mayúscula sea de aplicación tan subjetiva hace que reducir su empleo a un conjunto de normas claras sea sumamente complejo e inseguro. En cualquier otro aspecto ortográfico es posible configurar un compendio de reglas más o menos coherentes para su aplicación a la escritura [...], pero esto mismo no es fácilmente aplicable al empleo de las mayúsculas y las minúsculas. Y si bien podemos aceptar que la función demarcativa reduce notablemente la subjetividad, ello no puede afirmarse de la función distintiva, que, al basarse en la definición de nombre propio, abre un conjunto de posibilidades de interpretación tan amplio como escritores tiene la lengua [...]. Resultado de esta incoherencia es la inseguridad con que se afronta el estudio y el tratamiento de una materia como esta (Martínez de Sousa, 2007: 11-12).

Por otro, a excepción de la función demarcativa, cabe considerar la importancia o la necesidad que pueden tener en la comunicación las letras capitales:

Las mayúsculas podrían eliminarse de la escritura sin que nada se alterase. Es cierto que, puesto que existen, cumplen una función, pero el problema a que nos referimos estriba en que esa función está poco clara, muy enrevesada, hoy tanto como en tiempos pasados. Fiarlo todo al contexto es totalmente posible. Pero para ello, naturalmente, habría que explicar muy bien qué se entiende por nombre propio (Martínez de Sousa, 2007: 22).

A esto se añade el empleo de las mayúsculas con funciones subjetivas, no lingüísticas, propias de algunos ámbitos (OLE, 2010: 512-515) ${ }^{7}$.

Más importante, y que se extiende como crítica general de la obra, es la falta de normatividad, es decir, la ausencia de normas claras. Se espera de una obra académica

\footnotetext{
${ }^{6}$ Para un estudio más detallado, consúltese Gómez Torrego (2011).

${ }^{7}$ La Academia distingue la mayúscula diacrítica, que se aplica a aquellos sustantivos comunes que en una de sus acepciones designan una entidad o colectividad (Estado, Gobierno), pero que no está justificada en otros sustantivos como humanidad o naturaleza, de la mayúscula de relevancia, de carácter social, sacralizador y dignificador, aplicada a determinados referentes considerados con respeto o consideración (títulos y cargos como papa, rey...). Bajo esta segunda acepción se incluye también la llamada mayúscula enfática, de índole individual, que responde al deseo de subrayar determinadas palabras de interés para el autor, pero no por razones religiosas o ideológicas (partes de un texto en un escrito) o la que se aplica a sustantivos comunes a los que se les quiere dotar de un sentido más sublime (humanidad). En todos estos casos se recomienda no abusar de ella.
} 
que prescriba, que dé normas, no recomendaciones o sugerencias que provocan dudas o interpretaciones distintas, hecho que va en contra del criterio de unidad que es uno de los principios de la Asociación de Academias de la Lengua.

Incluso la normatividad del texto se pone en entredicho en la misma obra. Por ejemplo en la página 466 se nos dice que «a continuación se exponen las normas o recomendaciones de uso de mayúsculas y minúsculas [...]», es decir, que a veces exponen normas, y a veces, recomendaciones, que no es lo mismo! (Martínez de Sousa, 2011: 3).

A no ser que se entiendan las recomendaciones como normas:

El que se muestre dubitativa en cuanto a su carácter normativo o de simple recomendación, en lugar de pronunciarse a las claras y brindar rápidas soluciones, parece sugerir que muchas veces es la reflexión sobre los temas más importante que la conclusión. ¿O debe creerse que cuando la Academia recomienda en vez de normar está simplemente usando un recurso retórico para sonar menos dura y prescriptiva? (Riva Fort, 2011: 131).

Y, por último, la complejidad que entrañan algunas de ellas, que lo distancian del público medio o dificultan la asimilación de la «norma»o «recomendación», como vemos en los dos ejemplos siguientes en los que se sobreentienden conocimientos que quizá no estén tan extendidos entre un público no experto:

En los nombres de los espacios naturales protegidos solo es obligatoria la mayúscula en el término específico, no en los sustantivos y adjetivos genéricos que lo preceden: parque nacional de Doñana, parque natural de Paracé, reserva natural de Cabo Cruz. No obstante, es correcta la escritura de estos genéricos con mayúscula inicial cuando se trate de la denominación de la entidad o institución que gestiona estos espacios: Parque Nacional de Doñana. En ningún caso es admisible la mayúscula en usos puramente genéricos: El Gobierno creará una red de parques nacionales; Las competencias de gestión del parque natural están repartidas entre diversos organismos (OLE, 2010: 479).

Se escriben con mayúscula inicial los sustantivos y adjetivos que forman parte del nombre de las órdenes religiosas o religioso-militares; la Orden de los Predicadores, la Orden de San Agustín, la Orden del Temple, la Orden del Carmelo o del Carmen, la Orden Hospitalaria de San Juan de Dios, la Orden de la Cartuja, la Compañía de Jesús [...]. El sustantivo orden se escribirá con mayúscula inicial solo cuando forme parte del nombre propio de uno de estos institutos, pero no en sus referencias genéricas: El libro describe con realismo la dureza de los monjes de la orden; La regla de esta orden es especialmente estricta; Entró en la orden franciscana a los veinte años (el nombre propio de la orden franciscana es Orden de Frailes Menores) (OLE, 2010: 486-487).

Todo ello conlleva la consulta necesaria y continua de la Ortografía a la hora de trabajar documentos de determinados ámbitos, especialmente entre los profesionales del lenguaje, una obra, sin embargo, considerada densa y exhaustiva, de difícil manejo 
debido a la ausencia de un índice alfabético o al sistema de remisiones internas ${ }^{8}$. Posteriormente, la Academia publicó tres libros de carácter divulgativo, que, sin duda, facilitan la labor (Ortografía básica de la lengua española, Gramática básica de la lengua española y El buen uso del español). Así pues, el público general tiene a su alcance la normativa en publicaciones de bolsillo más cercanas a sus intereses, en las que se han omitido alternancias, se ha reducido la minuciosidad de algunas de estas cuestiones, o se han eliminado las más complejas, como los casos citados arriba (OBLE, 2012; EBUE, 2013) ${ }^{9}$.

Planteadas todas estas cuestiones y vista la importancia del reconocimiento visual de la palabra a la hora de «memorizar» su forma ortográfica, especialmente cuando carece de valor fonológico, como es el caso que nos ocupa, cabe considerar la función que tienen en la difusión de las normas las editoriales centradas en manuales escolares y los profesionales de este ámbito (autores, correctores y editores).

\section{NORMA Y EDICIÓN DE TEXTOS. ANÁLISIS DEL CORPUS}

Como hemos mencionado en la introducción, el corpus está formado por quince manuales escolares, que se corresponden con distintas editoriales, identificadas con un código, dedicadas exclusiva o casi exclusivamente a la docencia en las dos principales etapas educativas (Educación Secundaria y Bachillerato), de ámbito nacional o comunitario y en varias asignaturas, aunque se centren principalmente en las dedicadas a la «Lengua castellana y su literatura». Exceptuando algunas editoriales que no lo indican expresamente, en los manuales vaciados se comenta en la contraportada que se siguen las nuevas normas académicas, como ocurre así en general.

El corpus está constituido por ejemplos que ponen de manifiesto la «transgresión» o «separación» de las normas o recomendaciones académicas. El análisis del mismo se divide según la función de la mayúscula (demarcativa, identificativa, otras) y se acompaña de conclusiones. Quedan fuera del corpus las erratas de imprenta ${ }^{10}$.

\subsection{La función demarcativa de las mayúsculas ${ }^{11}$}

Con relación a la función demarcativa de las mayúsculas y en consonancia con la claridad de la normativa, cabe señalar que en general no hay ningún problema en el empleo de este tipo de letras con los signos de puntuación. Las mayúsculas se convierten así en un recurso visual útil para delimitar los enunciados.

\footnotetext{
${ }^{8}$ Estas y otras críticas en las reseñas de la obras consultadas (Martínez de Sousa, 2011; Riva Fort, 2011).

${ }^{9}$ También se pueden consultar publicaciones de carácter didáctico (Aleza, 2012), que facilitan la lectura de la Ortografía de 2010.

${ }^{10}$ En todas las editoriales es bien conocida la existencia de los «duendes de imprenta» y la presencia de las erratas. Se incluirán, en consecuencia, aquellos ejemplos que se repitan de forma sistemática o el uso incoherente e intermitente de algunos casos.

${ }^{11}$ Para delimitar las unidades textuales principales.
} 
No obstante lo dicho, se observa en los libros de texto analizados una diversidad de soluciones en el empleo de mayúsculas y minúsculas tras los dos puntos, que, «aunque [...] no señalan el final del enunciado, sí pueden anunciar el comienzo de una unidad con independencia de sentido» (OLE, 2010: 453). Así, se emplean mayúsculas en siete situaciones, dos de las cuales plantean problemas en los manuales consultados. Son las siguientes:

c) Tras los dos puntos que cierran los epígrafes o subtítulos de un libro o documento, o los elementos de una enumeración en forma de lista, cuando el texto explicativo que los sigue comienza en la misma línea ${ }^{12}$ :

La arquitectura egipcia: El elemento más característico de la arquitectura egipcia son las pirámides, construcciones funerarias que...

En esa región se crían gran variedad de setas:

- Trompeta de los muertos: Se trata de una seta comestible, con sombrero en forma de trompeta, especialmente adecuada para...

- Rebozuelo: Es una seta muy fácil de reconocer, de color amarillo o anaranjado...

\section{$[\ldots]$}

g) La primera palabra de cada uno de los elementos de una enumeración escritos en líneas independientes, siempre que estos se cierren con punto. Si se cierran con coma o con punto y coma, los mismos elementos comenzarán con minúscula (OLE, 2010: 453$)^{13}$.

En el corpus se observa que el uso de la minúscula es general en los índices:

(1) 2. Genoma: el libro de la vida (ED3, p. 4).

Pero no hay un criterio claro cuando se trata de las explicaciones en los epígrafes internos, aun tratándose del mismo manual.

Para algunas editoriales el único procedimiento empleado son los dos puntos, incluso a distintos niveles, marcados tipográficamente:

(2) b) Riesgos de origen humano:

- Degradación del suelo y deforestación: Se destruye la cubierta vegetal por la expansión de la agricultura y la ganadería, la expansión urbana, la tala de árboles y los incendios forestales.

$[\ldots]$

${ }^{12}$ Para ello se usa también la raya precedida del punto (OLE, 2010: 362 y 379) o el punto y el punto y raya (OBLE, 2012: 82 y 90).

${ }^{13}$ Este último caso no se encuentra en la OBLE, 2012. 
- La lluvia ácida: Caída de lluvia mezclada con ácido sulfúrico o nítrico que afecta a la vegetación y a los seres vivos.

- Efecto invernadero: El dióxido de carbono deja pasar los rayos solares como un cristal pero retiene el calor. Provoca sequía (ED11, p.11).

En otras ediciones alternan el punto y el uso de los dos puntos seguidos de minúscula en la misma página:

(3)... los siguientes elementos:

- Emisor: quien produce el mensaje, el texto... (ED5, p. $11)$.

(4) - Según la relación entre expresión y contenido: indicios, iconos y símbolos.

- Indicios. Son signos naturales... (ED5, p. 11).

O se resaltan los epígrafes con recuadros de colores, separados de la explicación con un punto, como en ED9.

\subsection{La función identificativa de la mayúscula ${ }^{14}$}

Como ya se ha indicado al hablar de las funciones de las letras mayúsculas, delimitar el nombre propio, el identificador, es tarea difícil y compleja por entrar en conflicto con lo que se considera o se puede considerar nombre propio y por tener límites muy próximos a la mayúscula de relevancia. Se han comentado también las dificultades que entrañan a veces la exhaustividad y minuciosidad de la obra académica y la falta de normas claras a este nivel. En consecuencia, son varios los casos que cabe mencionar en este apartado del corpus, algunos provocados por los nuevos cambios, otros estaban ya presentes en 2005 .

\subsubsection{Uso de las mayúsculas en los nombres propios referidos a personas}

\subsubsection{Tratamientos ${ }^{15}$}

Con relación a los tratamientos, la Academia (2010: 469) hace hincapié en que, si bien por respeto en el pasado se escribían con mayúscula inicial, «práctica que aún pervive en documentos oficiales y textos administrativos», todos ellos son adjetivos o sustantivos comunes, por lo que no hay razón para emplear la mayúscula. Así pues, deben escribirse con minúscula inicial todos los tratamientos, tanto los antenombres

\footnotetext{
${ }^{14}$ Para marcar los nombres propios y las expresiones denominativas.

${ }^{15}$ Apartado 4.3.4.1.5. pp. 469-470.
} 
(don, doña, fray, sor, santo/a), como los que pueden utilizarse sin él (usted, señor/ra, doctor $/ \mathrm{ra})^{16}$.

Esta es la solución general en los libros de texto, incluso con los personajes literarios (doña Jimena, doña Elvira, doña Sol, doña Endrina, don Quijote, don Pablos, fray Luis, san Juan, san Marcos), aunque se puede detectar alguna errata no sistemática o se mantiene en los títulos de los libros:

(5) En el 711 un ejército dirigido por Tariq desembarcó en Gibraltar y derrotó al último rey visigodo, Don Rodrigo, en la batalla de Guadalete. (ED12, p.127).

(6) ... las experiencias místicas de San Juan... (ED6, p. 202).

(7) Vida de San Millán [...] Vida de Santo Domingo (ED4, p. 322).

\subsubsection{Títulos y $\operatorname{cargos}^{17}$}

Entre las novedades de OLE (2010) sigue levantando polémica el uso de la minúscula con los sustantivos que designan títulos nobiliarios, dignidades y cargos o empleos de cualquier rango (ya sean civiles, militares, religiosos, públicos o privados), dada su condición de nombres comunes, tanto en usos genéricos (El rey reina, pero no gobierna; El papa es la máxima jerarquía del catolicismo; El presidente de la república es un cargo electo) como en menciones referidas a una persona concreta (La reina inaugurará la nueva biblioteca...). De hecho, aún hoy la mayúscula sigue siendo la opción más generalizada en los medios de comunicación escritos cuando se refieren a los miembros de la familia reinante en España ${ }^{18}$, manteniendo de este modo en este ámbito la postura académica expuesta en el $D P D^{19}$, en la que se establecían los

16 Añade la Academia: «Para aquellas fórmulas honoríficas correspondientes a las más altas dignidades en el tratamiento protocolario (su santidad, su majestad, su excelencia...), la mayúscula inicial es admisible -aunque no obligada- solo si el tratamiento no va seguido del nombre propio de la persona a la que se refiere: La recepción a Su Santidad será en el palacio arzobispal» (OLE, 2010: 470). La mayúscula inicial se mantiene en las abreviaturas o en los casos en los que el tratamiento forma parte del nombre propio, como en San Cristóbal de las Casas (ciudad de Chiapas, México) o San Fermín (festividad). Es por ello que se modifica el apartado 6.8 del artículo sobre las mayúsculas del $D P D$, en el que se admitía la mayúscula solo si se habían formado acuñaciones que funcionaban como nombres propios en la tradición (Fray Luis, referido a fray Luis de León; Sor Juana, referido a sor Juana Inés de la Cruz; Santa Teresa, referido a Santa Teresa de Jesús).

${ }^{17}$ Apartado 4.2.4.1.6. pp. 470-471.

${ }_{18}$ Se pueden encontrar numerosos ejemplos en que se vacila entre el uso de la mayúscula y la minúscula tanto en los antenombres como al referirse al cargo: el rey Felipe VI / el Rey Felipe VI; el Rey emérito Don Juan Carlos...

19 «4.31. Los títulos, cargos y nombres de dignidad, como rey, papa, duque, presidente, ministro, etc., que normalmente se escriben con minúscula, pueden aparecer en determinados casos escritos con mayúscula. Así, es frecuente, aunque no obligatorio, que estas palabras se escriban con mayúscula cuando se emplean referidas a una persona concreta, sin mención expresa de su nombre propio: El Rey inaugurará la nueva biblioteca; El Papa visitará la India en su próximo viaje. Por otra parte, por razones de respeto, los títulos de los miembros de la familia reinante en España suelen escribirse con mayúscula, aunque vayan seguidos del nombre propio de la persona que los posee, al igual que los tratamientos de don y doña a ellos referidos: el Rey Don Juan Carlos, el Príncipe Felipe, la Infanta Doña Cristina. También es costumbre particular de las leyes, decretos y documentos oficiales, por razones de 
contextos en que debía escribirse con letras mayúsculas por motivos de respeto y solemnidad; y ello a pesar de la recomendación actual de acomodarlos también a la norma general ${ }^{20}$.

Esta vacilación, que encontramos en la prensa escrita, se observa en algunos de los manuales escolares, en contextos en los que no debería aparecer la mayúscula:

(8) el Rey Alfonso VI (ED1 Lit., p. 61)/ el rey Alfonso VI (ED1 Lit., p. 66).

(9) el rey Luis XIV; el papa visitó Valencia (ED15, p. 223).

Esta norma afecta también a los títulos de obras de creación literaria, en los que las editoriales respetan la normativa en algunos casos: El conde Lucanor (ED4, p. 323; ED6, p. 82; ED10, p. 59), pero no en otros: El mejor alcalde, el Rey (ED4, p. 468). No obstante, de nuevo destaca la presencia en algunas editoriales de vacilaciones incluso en la misma página, hecho que demuestra la incoherencia de algunas soluciones editoriales:

(10) Libro del conde Lucanor (ED1 Lit., p.78).

(11) El conde Lucanor (título) (ED1 Lit., p.81) / El Conde Lucanor (en pie de ilustración) (ED1Lit., p. 81).

\subsubsection{Uso de las mayúsculas en nomenclaturas científicas ${ }^{21}$}

En los manuales de asignaturas como Biología o Geología, la escritura de las nomenclaturas científicas suele responder a la normativa vigente, en cursiva, con mayúscula solo el primer miembro del taxón y artículo en redonda:

(12) El Euzomodendron bourgaeanum (ED2, p. 266).

Esta norma se incumple en algunas editoriales, especialmente cuando emplean en las actividades textos extraídos de determinados medios de comunicación o redes sociales en las que no se ha respetado. Se plantea de este modo la cuestión de si hay que mantener el escrito original o adaptarlo a la normativa o si cabe marcar los cambios, sobre todo cuando el material, como ocurre con frecuencia, es anterior a 2010:

(13) Se trata de Lucy, una Australopithecus afarensis de poco más de un metro (ED12, p. 54).

solemnidad, escribir con mayúsculas las palabras de este tipo: el Rey de España, el Jefe del Estado, el Presidente del Gobierno, el Secretario de Estado de Comercio. Por último, es muy frecuente que los cargos de cierta categoría se escriban con mayúscula en el encabezamiento de las cartas dirigidas a las personas que los ocupan» (DPD, 2005).

${ }^{20}$ Aunque por razones de solemnidad y respeto, se acostumbra a escribir con mayúscula inicial los nombres que designan cargos o títulos de cierta categoría en textos jurídicos, administrativos y protocolarios, así como en el encabezamiento de las cartas dirigidas a las personas que los ocupan u ostentan, se recomienda acomodarlos también en estos contextos a la norma general y escribirlos con minúscula (OLE, 2010: 470-471).

${ }^{21}$ Apartado 4.2.4.5.2. pp. 473-474. 
(14) Uno de los habitantes más famosos y mediáticos es «Miguelón», el cráneo número 5 de la Sima de los Huesos, un homo heidelbergensis hallado en 1992. (ED12, p. 66).

(15) de un individuo del Peistoceno Medio de la especie Homo Heidlebergensis (ED12, p. 83).

\subsubsection{Uso de las mayúsculas en los nombres propios referidos a lugares}

\subsubsection{Accidentes geográficos y otras denominaciones de lugares ${ }^{22}$}

Respecto al nombre de continentes, países y ciudades no suele haber ningún tipo de dificultad en el corpus trabajado. Sin embargo, el problema se plantea en los nombres pluriverbales que incluyen en su denominación un sustantivo genérico de carácter geográfico, que debe ir también en mayúscula (Cabo Verde, Países Bajos, etc.), para distinguirlos de aquellos en que el sustantivo genérico funciona como categorizador y debe ir en minúscula por no formar parte del nombre propio (la ciudad de Panamá).

Este segundo caso es el que plantea dudas pues es difícil determinar si forma parte del nombre propio o no, tal como se indica en la propia obra académica, que da las siguientes pautas para su reconocimiento (OLE, 2010: 462-463): a) cuando el sustantivo genérico denota una realidad que no se corresponde con el referente, por ejemplo, Cabo Verde, que no es un cabo sino un país; b) cuando la expresión denominativa no exige la anteposición del artículo para integrarse en el enunciado (Pasé mis vacaciones en Ciudad del Cabo); c) cuando el término específico no es el que habitualmente se utiliza para referirse al tipo de realidad (Picos de Europa).

A pesar de ello, en ocasiones sigue resultando difícil reconocer la expresión denominativa. Es el caso de País de Gales (ED2, p.10). La Academia recomienda escribir el país de Gales (OLE, 2010: 475), por tratarse de un sustantivo categorizador, dado que el nombre oficial de la nación es Gales. Hay que entenderlo, por tanto, como denominación que corresponde a una división administrativa, en la que solo está justificado el uso de la mayúscula en el término específico (el condado de York, la pedanía de Lorca, el concejo de Mieres...) (OLE, 2010: 479). No obstante, una rápida ojeada a algunas guías turísticas permite concluir que está extendido este nombre como equivalente español a una de las naciones que conforman Reino Unido.

Con relación a los nombres propios de los accidentes geográficos, tanto naturales como artificiales, ya se ha indicado antes que se escribe con mayúscula inicial el término específico, pero no los sustantivos comunes genéricos que los acompañan (océano, mar, río, sierra, cabo, golfo, canal), a no ser que se usen antonomásticamente:

(16) A ambos lados del canal de la Mancha (ED2, p. 10).

En este apartado cabe mencionar una de las novedades de la última Ortografía, que desdice lo expuesto en ediciones anteriores. Nos referimos a la escritura en minúscula de península ibérica. Si bien con anterioridad se contemplaba la escritura en

${ }^{22}$ Apartados 4.2.3.1.3. pp. 462-463 y 4.2.4.6.3. pp. 476-478. 
minúscula de los accidentes geográficos ${ }^{23}$, se excluía de esta regla a la denominación que nos ocupa ${ }^{24}$. La Academia añade ahora una explicación extensa:

Cuando para referirse a un accidente geográfico se emplea el sustantivo genérico seguido de un adjetivo derivado del topónimo al que dicho accidente corresponde -se trate del topónimo actual o de una variante ya en desuso-, tanto el sustantivo genérico como el adjetivo se escriben con minúscula: cordillera andina (el adjetivo andino deriva del topónimo Andes), meseta castellana (el adjetivo castellano deriva del topónimo Castilla), islas británicas (el adjetivo británico deriva del topónimo histórico Britania), península ibérica (el adjetivo ibérico deriva del topónimo histórico Iberia) o península itálica (el adjetivo itálico deriva del topónimo Italia). Se trata, en estos casos, de expresiones meramente apelativas o comunes, aunque designen un referente único. Es necesario diferenciar estos casos de aquellos en los que el adjetivo va con mayúscula inicial por no derivar de un topónimo previo y ser, por tanto, la parte genuinamente propia de la denominación, como mar Mediterráneo, mar Rojo, islas Canarias, islas Aleutianas, etc. (OLE, 2010: 477).

Se mantiene, sin embargo, la posibilidad de emplear la mayúscula en los usos antonomásticos (la Península).

Este es el uso extendido en la mayoría de los manuales, aunque sigue habiendo editoriales que no han aplicado la norma, bien por desconocimiento, bien por tratarse de una reimpresión, bien por confundir los usos de las mayúsculas, hecho que debería ser evitado en un texto dirigido a estudiantes:

(17) Los musulmanes se establecieron en la península ibérica como consecuencia de la expansión del islam. [...] En apenas cuatro años se produce una rápida ocupación de la Península, tanto a través de rendiciones pactadas, la mayoría, como de rendiciones incondicionales (ED12, p. 127).

(18) De ahí la entrada en la Península de préstamos del provenzal u occitano (ED6, p. 31).

(19) El reino de Castilla había ocupado todo el centro de la Península (ED10, p. 8).

(20) En esta zona se originan sismos que afectan a la costa oeste de la Península Ibérica y algunas veces producen tsunamis (texto adaptado, también en preguntas) (ED2, p. 42).

(21) Península Ibérica (ED1 Lit., p. 33).

(22) Desde el siglo XI, la península (ED1 Lit., p. 33).

\subsubsection{Espacios naturales protegidos ${ }^{25}$}

Como ya se ha mencionado más arriba al hablar de las dificultades que entraña para el público medio la Ortografía, uno de las normas que causan dudas es la mayúscula del término genérico al referirnos a los espacios naturales protegidos, sobre

${ }^{23}$ Apartado 3.3.2.b), (OLE, 1999: 33) y apartado 4.7. (DPD, 2005).

${ }^{24} \mathrm{El}$ hecho de escribir Península Ibérica con mayúsculas se debe a que con esta expresión nos referimos a una entidad de carácter histórico-político, y no a un mero accidente geográfico (DPD, 2005, 4.7.)

${ }^{25}$ Apartado 4.2.4.6.6. p. 479. 
todo en comunidades bilingües en los que las denominaciones pueden aparecer en varios idiomas, con normativa distinta tanto para el uso del artículo como de la mayúscula, por ejemplo:

(23) P.N. de La Albufera, P.N. del Montgó, P.N. del Carrascal de la Font Roja P.N. de Las Lagunas de la Mata y Torrevieja P.N. de Las Salinas de Santa Pola P.N del Peñón de Ifach, Paraje Natural del Desert de Les Palmes, Reserva Natural de Las Islas Columbretes, Reserva (Marina) Natural de la Isla de Tabarca, Reserva (Marina) Natural del Cabo de San Antonio (ED12, cuadro p.14).

\subsubsection{Uso de las mayúsculas en los nombres propios referidos a entidades ${ }^{26}$}

En el corpus trabajado no existen vacilaciones en el empleo de las mayúsculas para marcar todos los elementos que conforman la denominación de organismos, instituciones o departamentos:

(24) Centro de Biología Molecular «Severo Ochoa» (CSIC-UAM) y miembro de la RAE; investigador del Centro Nacional de Biotecnología (CSIC); responsable de la Oficina de Información de la FAO en España; profesor del Departamento de Física (ED3, p. 6).

(25) Real Academia Española (ED15, p. 223).

Tampoco cuando se emplea la mayúscula para marcar el sustantivo común que remite a una entidad:

(26) La figura de la mujer logra una importancia sin precedentes dentro de la Iglesia (ED4, p. 318)

Los problemas surgen al referirse a formas de Estado y de gobierno, que se escriben con mayúscula inicial si el sustantivo forma parte de la denominación (Reino de España, República Argentina), pero no si no se corresponde con el nombre oficial (república mexicana, ya que la denominación oficial de México es Estados Unidos Mexicanos), lo que dificulta la escritura a veces de estos nombres. Esta duda se traslada también a las formas de gobierno de períodos anteriores:

(27) En el siglo XIII Jaime I, monarca de la Corona de Aragón, conquistó las tierras valencianas a los musulmanes y fundó en ellas el Reino de Valencia. (ED12, p. 131).

(28) La vida de Gracián transcurrió íntegramente en los territorios de la corona de Aragón. (ED4, p. 423).

(29) el reino de Castilla había ocupado todo el centro de la Península (ED10, p. 8).

${ }^{26}$ Apartado 4.2.4.7., pp. 482-487. 
3.2.5. Uso de las mayúsculas en las denominaciones relacionadas con la actividad intelectual o cultural del hombre

\subsubsection{Títulos $^{27}$}

Al estar compuesto el corpus en su mayoría por libros de texto de la asignatura de «Lengua castellana y literatura», es frecuente la presencia en sus páginas de títulos de obras literarias. Tal como señala la Academia, en español se debe escribir en mayúscula inicial únicamente la primera palabra del título de una obra de creación, sea un libro, un cómic, una película, una pieza musical, etc. (Libro de buen amor, Divina comedia, Mujeres al borde de un ataque de nervios, Diccionario de la lengua española, Diccionario panhispánico de dudas, Ortografía de la lengua española), puesto que la cursiva marca los límites del nombre propio. Añade además una especificación que no se hallaba en el artículo sobre las mayúsculas del $D P D$ :

Esta norma debe aplicarse a los títulos de todas las obras de creación, incluidas aquellas pertenecientes a épocas en las que, por no estar aún fijadas las normas ortotipográficas, era habitual aplicar la mayúscula más allá de la palabra inicial; así, debe escribirse Libro de buen amor o Divina comedia, en lugar de *Libro de Buen Amor o *Divina Comedia, como ha sido normal hasta ahora. El artículo que antecede a la mención de ciertas obras de creación no siempre pertenece al título y, en ese caso, debe escribirse con minúscula y en redonda; así ocurre en casos como la Odisea, la Ilíada o la Divina comedia (OLE, 2010: 488).

Dada la tendencia a la simple reimpresión o a los «refritos» fruto de los constantes cambios en la normativa educativa y a cuestiones de otra índole que mueven a las editoriales, no es extraño comprobar en los manuales que no se ha aplicado este pequeño cambio o, de nuevo, que no hay unas directrices claras en la editorial:

(30) Libro de Buen Amor (ED1 Lit., p.34) (ED11, p. 176) / Libro de buen amor (ED4, p. 333; ED6, p. 78; D10, p. 59).

(31) Dante y su Divina Comedia (ED4 p. 318) / Divina comedia (ED4, p. 499).

Más dudas surgen cuando se toma en consideración la inclusión o no inclusión del artículo:

(32) El Cantar de Mio Cid, La Iliada, La Odisea (ED1 Lit., p. 10).

(33) desde el Auto de los Reyes Magos (ED1 Lit., p. 86) / El Auto de los Reyes Magos (ED1 Lit., p. 88).

(34) Los más importantes fueron El Cancionero de Baena y el Cancionero de Stúñiga (ED1 Lit., p. 44).

\footnotetext{
${ }^{27}$ Apartado 4.2.4.8.1. pp. 487-493.
} 
En el Diccionario panhispánico de dudas (2005: 4.17) ya se indicaba que en el caso de los títulos abreviados con que se conocen comúnmente algunas obras literarias, el artículo que los acompaña debe escribirse con minúscula. En OLE (2010) se especifica además que el artículo ha de estar en letra redonda (el Quijote, la Celestina, el Lazarillo) y, en consecuencia, se debe realizar la contracción del artículo con las preposiciones $a$ y de, si corresponde (al Quijote, del Quijote). Cada vez son más las editoriales que dan cuenta de este cambio, excepto en uno de los títulos (la Celestina). En aquellas que no lo siguen, tampoco hay una postura clara, por lo que incluso en la misma página se puede ver escrito de distinta manera, lo que perjudica la memoria visual de la expresión:

(35) El Lazarillo (ED1 Lit. p.22) / el Lazarillo (ED6, p. 327; ED10, p. 153; ED11, p. 209).

(36) El Quijote (ED1 Lit., p. 22; ED3, p. 24 / el Quijote (ED4, p. 344, 392; ED5, p. 21; ED6, p. 212, ED10, p.171, ED11, p. 212).

(37) La Celestina (ED1, p.33, p. 90, ED4, p. 324, 368; ED5, p. 1, p. 58; ED10, 102, ED11, p. 182) / la Celestina (ED4, p. 324; ED6, p. 86).

(38) el Quijote es, a su modo, un libro de caballerías (ED4, p. 404).

(39) su última obra, el Persiles, publicada póstumamente en 1617 (ED4, p. 405).

(40) El recuerdo del Lazarillo (...) se hace entonces inevitable (ED4, p. 415).

(41) La Celestina se inscribe dentro del género... (ED6, p. 87).

(42) a la favorable acogida que tuvo el Guzman, la obra evoca la sombra del Lazarillo, ... (ED6, p. 327).

(43) en el Buscón no hallamos un caso que motive la revisión de su vida (ED6, p. 327).

\subsubsection{Disciplinas científicas ${ }^{28}$}

En cuanto a las ramas de conocimiento, la norma general es el uso de la minúscula (La física nuclear ha experimentado grandes avances en los últimos años), a excepción de que designen estudios o materias regladas (Soy licenciada en Física). Cuando los sustantivos y adjetivos forman parte del nombre de una asignatura o materia de estudio se escriben con mayúscula inicial, coincida o no con el nombre de una ciencia o disciplina (Inglés, Conocimiento del Medio). En el caso de que el nombre sea demasiado largo (Normas y usos correctos del español actual), ha de emplearse la mayúscula inicial tan solo en la primera palabra y, al citarlo, ha de indicarse el nombre completo mediante otros procedimientos (comillas).

En el corpus trabajado se puede observar la confusión entre el nombre de la disciplina y de la asignatura, incluso en la misma página (ED2, p. 7):

${ }^{28}$ Apartado 4.2.4.8.3, pp. 493-494. 
(44) La biología y la geología son ciencias de la naturaleza. [...] En la elaboración de este manual de Biología y Geología $1 .^{\circ}$ de bachillerato ... [...] Se hace alusión asimismo a las investigaciones más punteras en Biología y Geología para que los estudiantes comprendan que la ciencia es un proceso vivo. [...] La Geología debe ser estudiada...

Incluso se puede hablar de una falta de criterio, por no arriesgarnos a señalar el uso ideológicamente marcado de mayúsculas y minúsculas, como se puede interpretar en el siguiente ejemplo, que parece distinguir entre las disciplinas «útiles» $\mathrm{y}$ «no útiles» (ED3, p. 13):

(45) El mundo actual no puede entenderse solo desde la Economía, la política, la literatura, la filosofía o el Derecho; pero tampoco desde la Física, la Química, la Geología o la Biología exclusivamente.

3.2.6. Uso de las mayúsculas en las referencias temporales, cronológicas o históricas

Al hablar de los nombres referidos a períodos y acontecimientos históricos, debe emplearse la mayúscula inicial en cada uno de los elementos de la expresión. Hallamos, no obstante, algún ejemplo que no cumple esta norma, probablemente por error:

(46) reconquista (ED1 Lit., p. 64)/ Reconquista (ED1, Lit. p. 68); con la Reconquista (ED10, p. 3).

(47) del Siglo de Oro (ED9, p.177); Siglo de las Luces (ED9, p. 250).

(48) Con el descubrimiento de América (ED10, p. 27).

(49) El Humanismo nació en Italia (...) El Renacimiento (ED10, p. 123); Esta reacción dará lugar a un movimiento religioso y político denominado Contrarreforma (ED4, p. 364).

(50) Primera Guerra Mundial, Edad Media (ED15, p. 223).

En cambio, en las denominaciones de los diferentes imperios tanto si se refieren al período de tiempo como al conjunto de territorios que lo conforman, imperio debe escribirse con mayúscula, pero no el especificativo subsiguiente, a no ser que contenga un nombre que lo exija:

(51) Imperio turco (ED4, p. 365); Imperio romano de Occidente (ED4, p. 317); La caída del Imperio romano (ED10, p.3) / Imperio Romano (ED1 Lit., p. 33).

En el caso de las revoluciones, se escriben con mayúscula los sustantivos y los adjetivos que forman los nombres, salvo si el adjetivo especificativo expresa una nacionalidad:

(52) ... la Revolución francesa comenzó el período más fructífero de la humanidad (ED3, p.15), pero la Revolución Industrial (ED13, p. 282). 


\subsection{Uso de la mayúscula de relevancia ${ }^{29}$}

Dado el carácter didáctico del corpus manejado, es frecuente el empleo de recursos tipográficos y de otra índole para destacar las palabras clave del tema o los conceptos que se introducen por primera vez. Si bien con estas funciones es más propio emplear otros procedimientos como la negrita o la cursiva, en algunos manuales se usa la mayúscula con este fin. En los siguientes ejemplos extraídos de la misma página del manual (ED1 Lit., p. 41), llama la atención el empleo innecesario de la mayúscula por coincidir con otros recursos, además de la asistematicidad con la que se utilizan:

(53) tanto en las Jarchas como en las Cántigas de Amigo y en los villancicos castellanos...

Lírica Española de tipo popular

Las Canciones eran...

También con este valor se aplica la mayúscula a aquellos términos cuyos referentes quieren subrayarse y que, aún no teniendo una razón lingüística, se usan para marcar personificaciones o acepciones elevadas o sublimes:

(54) En la Danza, el personaje de La Muerte (ED4, p. 86).

(55) la contemplación de la belleza femenina [...] le permite acceder al conocimiento de la Belleza Absoluta (ED4, p. 368).

\section{CONCLUSIONES}

Como ya se ha señalado en la introducción, el propósito de este artículo consistía en analizar el uso de las mayúsculas en la edición de manuales de texto posteriores a la $O L E$ (2010) y determinar los aspectos que plantean mayores problemas u ofrecen diferentes soluciones para extraer conclusiones sobre la dificultad que entraña su empleo o la carencia de normas claras al respecto, con la finalidad última de divulgar los aspectos pendientes de una mejor regulación, hacer hincapié en la importancia de criterios claros en la aplicación práctica de las normas y en la responsabilidad de los profesionales.

Tras el estudio pormenorizado de un corpus extraído obtenido del vaciado de una serie de manuales escolares correspondientes a diferentes editoriales, niveles educativos y asignaturas, se puede llegar a las siguientes conclusiones:

a) En relación con la función demarcativa de este tipo de letras, se han hallado diferentes soluciones al empleo de la mayúscula o minúscula tras dos puntos. Cada editorial, y no de manera sistemática, introduce de distinto modo las explicaciones después de un epígrafe o subtítulo interno, consecuencia de falta de claridad en la exposición de ese artículo Sería necesario, pues, especificar qué se entiende

\footnotetext{
${ }^{29}$ Apartado 4.6. pp. 814-815.
} 
exactamente por epígrafe o subtítulo interno ya que se incorpora en la explicación también el concepto de lista.

b) Sin duda, la función identificativa de la mayúscula es la que plantea mayores dificultades, pues guarda relación con el concepto de nombre propio.

c) El corpus analizado recoge los cambios más recientes, sobre todo aquellos que tienen mayor repercusión social y han sido objeto de polémica en los medios de comunicación y en las redes sociales. Tal es el caso de las modificaciones relativas a los tratamientos y a los títulos o cargos (rey, papa, don Felipe), en las que existe cierta permisividad por parte de la Academia a la hora de seguir admitiendo ciertos usos marcados por la tradición, que deberían quedar relegados a contextos más protocolarios.

d) En ocasiones, el error o la vacilación se debe a la dificultad que entraña conocer la opción correcta, pues supone conocimientos extralingüísticos. Es el caso de los parajes naturales, de los nombres de las órdenes religiosas o de los países (parque natural de Doñana, orden franciscana, país de Gales, república mexicana...).

e) La densidad y complejidad de la obra académica, el sistema de remisiones internas y la falta de índice alfabético no favorecen su consulta. En los manuales analizados más cercanos en el tiempo a la publicación de la $O L E$, se observan algunos fallos debidos, probablemente, a la necesidad de una lectura más profunda.

En relación con la labor de los profesionales de la edición de textos escolares, cabe señalar la responsabilidad y seriedad de muchas de las editoriales en la salvaguarda de las normas ortográficas en el aspecto objeto de este trabajo. No obstante, hay que insistir en la necesidad de directrices claras en los libros o normas de estilo de las editoriales, pues, con demasiada frecuencia, se han ejemplificado soluciones diferentes ante la opcionalidad de la Academia, fruto de los diferentes correctores. En nuestra opinión, ante dos posibilidades válidas, se debería elegir solo una y mantenerla en todos los libros o, al menos, a lo largo del mismo manual. Además, se debería tener más cuidado en las reimpresiones y reediciones de los manuales, sobre todo cuando se produce un cambio normativo que afecta a todos los niveles de la lengua como ha sido este. A todo ello se puede añadir la conveniencia de contar con una asesoría en diversos temas, especialmente en aquellos puntos en que tiene que haber una mayor formación cultural, política, histórica, etc. Por último, habría que considerar el hecho de marcar los cambios o adaptar los materiales externos empleados en las actividades para no generar confusión entre quienes son destinatarios finales del libro.

Aparte de las funciones lingüísticas de las mayúsculas, se han comentado también sus usos enfáticos o subjetivos. Dado que se trata de un ámbito académico, destinado a un público en formación, hay que evitar estos empleos de realce de las mayúsculas, puesto que existen otros medios para este fin. 
CORPUS

ED1 Editorial de ámbito nacional. Primero de Bachillerato. Asignatura: Lengua castellana y literatura. Dos cuadernillos: uno dedicado a Lengua y otro a Literatura. Valencia, 2012.

ED2 Editorial de ámbito nacional. Primero de Bachillerato. Asignatura: Biología y Geología. Madrid, 2012.

ED3 Editorial de ámbito nacional. Primero de Bachillerato. Asignatura: Ciencias del mundo contemporáneo. Madrid, 2012.

ED4 Editorial de ámbito nacional. Primero de Bachillerato. Asignatura: Lengua castellana y literatura. Reimpresión Madrid, 2011. Primera edición 2003.

ED5 Editorial de ámbito nacional. Primero de Bachillerato. Asignatura: Lengua castellana y literatura. Madrid. 2012.

ED6 Editorial de ámbito comunitario. Primero de Bachillerato. Asignatura: Lengua castellana y literatura. Valencia, 2014. Primera edición 2012.

ED7 Editorial de ámbito nacional. Cuarto de ESO. Asignatura: Lengua castellana y literatura. Vol. 2. Madrid, 2012.

ED8 Editorial de ámbito nacional. Cuarto de ESO. Asignatura: Lengua castellana y literatura. Zaragoza, 2011.

ED9 Editorial de ámbito nacional. Tercero de ESO. Asignatura: Lengua castellana y literatura. Vol. 3. Madrid, 2011.

ED10 Editorial de ámbito nacional. Tercero de ESO. Asignatura: Lengua castellana y literatura. Barcelona, 2011.

ED11 Editorial de ámbito nacional. Tercero de ESO. Asignatura: Lengua castellana y literatura. Bloque literatura. Barcelona, 2011.

ED12 Editorial de ámbito comunitario. FP Básica 1. Asignatura: Comunicación y sociedad. Valencia, 2014.

ED13 Editorial de ámbito nacional. Tercero de ESO. Asignatura: Ámbito lingüístico y social. Madrid. 2011.

ED14 Editorial de ámbito nacional. Primero de ESO. Asignatura: Lengua castellana y literatura. Barcelona, 2010.

ED15 Editorial de ámbito nacional. Primero de ESO. Asignatura: Lengua castellana y literatura. Madrid, 2011.

\section{REFERENCIAS BIBLIOGRÁFICAS}

AlezA IzQuiERDO, Milagros (2012): «La letra mayúscula» (capítulo 5), Signos ortográficos, ortotipografía y normas actuales, Anejo 1 de Normas. Revista de Estudios 
Lingüísticos Hispánicos, Valencia, Universitat de València, 107-117, 2. ${ }^{a}$ ed. [en línea]: <https://www.uv.es/normas/Signos_2012>.

AleZA IZQUIERDO, Milagros, coord. (2013): Normas y usos correctos en el español actual, Valencia, Tirant Humanidades, 2. ${ }^{\mathrm{a}}$ ed. corregida y actualizada.

BRAVO CóPPOLA, Laura (2004): «Las destrezas perceptuales y los retos en el aprendizaje de la lectura y la escritura. Una guía para la exploración y comprensión de dificultades específicas», Actualidades Investigativas en Educación (Revista Electrónica), 4, núm. 1.

Clemente LinUeSA, María (1984): «El aprendizaje de la lectoescritura. Aspectos de su problemática y algunas perspectivas actuales», Enseñanza \& Teaching (Revista Electrónica), 2.

GÓMEZ TORREGO, Leonardo (2011): Las normas académicas: últimos cambios. Madrid, SM.

GONZÁLEZ LAS, Catalina (1999): «La enseñanza de la ortografía. Análisis de su tratamiento en los libros de texto de la educación primaria» [en línea]: <http://ruc.udc.es/bitstream/2183/8089/1/LYT_14_1999_art_7.pdf > . [Consulta: 10/09/2014].

InSTITUTO CERVANTES (2012): El libro del español correcto. Claves para hablar y escribir bien en español, Barcelona, Espasa Libros.

LA RIVA FORT, José Antonio de (2011): «Utilidad de la nueva Ortografía de la lengua española para el profesional del lenguajes», Panace@, 12, núm. 33, Primer semestre [en línea]: 〈http://tremedica.org/panacea.html>. [Consulta: 10/09/2014].

MARTíNEZ DE SOUSA, José (2003): «La "nueva” ortografía académica» [en línea]: <www.martinezdesousa.net/nuevaorto-academia.pdf >. [Consulta: 10/09/2014].

MARTínez DE SOUSA, José (2007): Diccionario de uso de mayúsculas y minúsculas, Gijón, Trea.

MARTíNEZ DE SoUSA, José (2011): «La nueva ortografía académica del 2010: cara y dorso» [en línea]: 〈www.martinezdesousa.net/crit_ole2011.pdf $>$. [Consulta: 10/09/2014].

PAREDES, Florentino (1997): «La ortografía: una visión multidisciplinar», Actas del VIII Congreso de la Asociación de Academias de la Lengua Española [en línea]: $<$ http://cvc.cervantes.es/Ensenanza/biblioteca_ele/asele/pdf/08/08_0607.pdf $>$.

[Consulta: 10/09/2014].

PAREDES, Florentino (1999): «La ortografía en las encuestas de disponibilidad léxica», REALE, Revista de Estudios de Adquisición de la Lengua Española, 11, 75-97.

PINO, Mónica y Luis BRAVO (2005): «La Memoria Visual Como Predictor del Aprendizaje de la Lectura», Psykhe, 14, núm. 1, 47-53, $<$ http://dx.doi.org/10.4067/s0718-22282005000100004>.

REAL ACADEMIA ESPAÑOla (1999): Ortografía de la lengua española. Edición revisada por las Academias de la Lengua Española, Madrid, Espasa Calpe [OLE, 1999].

REAl ACADEMIA ESPAÑola (2001): Diccionario de la lengua española, Madrid, Espasa, 22. ${ }^{\text {e }}$ ed. [DRAE]. 
Real ACADEMia Española y Asociación de ACADEMias de la Lengua ESPAÑOLA (2012): Ortografía básica de la lengua española, Barcelona, Espasa Libros [OBLE, 2012].

Real ACAdEMia Española y Asociación de ACAdemias de la Lengua EsPaÑOLA (2005): Diccionario panhispánico de dudas, Madrid, Santillana. [DPD]

REAL ACADEMIa EsPañola y ASOCIACión DE ACADEMIAS DE LA LENGUA ESPAÑOLA (2010): Ortografía de la lengua española, Barcelona, Espasa Libros [OLE, 2010].

Real ACAdEMia Española y Asociación de ACADEMias DE LA LENGUA ESPAÑola (2013): El buen uso del español, Barcelona, Espasa Libros [EBUE, 2013].

\section{ABREVIATURAS}

OBLE (2012): Ortografía básica de la lengua española.

OLE (1999): Ortografía de la lengua española.

DRAE (2001): Diccionario de la lengua española, 22. ${ }^{\text {a ed. }}$

DPD (2005): Diccionario panhispánico de dudas.

OLE (2010): Ortografía de la lengua española.

EBUE (2013): El buen uso del español. 